\section{THU0595 THE VIEWS AND PERCEPTIONS OF NON-SPECIALIST, HOSPITAL JUNIOR DOCTORS ON JOINT ASPIRATION OF THE ACUTE HOT-SWOLLEN-JOINT, AND THEIR TRAINING IN THIS CLINICAL SKILL}

Z. Farah. Rheumatology, Imperial Healthcare Trust, London, United Kingdom

Background: BSR guidance on managing hot-swollen-joints recommends early joint aspiration (arthrocentesis) to rule out septic arthritis and avoid morbidity and mortality. In such patients, the initial assessment is often performed by junior doctors prior to specialist review. Previous audit suggests poor adherence to recommended guidance. Our previous quantitative survey in 2 hospitals found low self-reported confidence at managing hot-swollen-joints in 72 of $140(52 \%)$ respondents; 58 (42\%) participants reported inadequate exposure, and $43(31 \%)$ inadequate training. There is limited research exploring the reasons behind poor uptake of arthrocentesis by junior doctors.

Objectives: To determine the perceptions of junior doctors about joint aspirations, their training to perform this important skill and how training could be improved Methods: The focus group included two foundation doctors, two senior houseofficers and two registrars. Focus group questions were developed from themes that emerged from our previous quantitative survey. The session was recorded using an iPhone, then anonymously transcribed verbatim. The transcript was analysed using an emergent coding technique drawn from grounded theory approach. The data was coded over three passes.

Results: Decision to aspirate a joint appeared to be influenced by internal and external factors. Internal factors included their previous experience, which was variable with one who "did 7 aspirations" and another who "[had] not had any experience at all." Other factors like anatomical knowledge, level of seniority and prior training were presented. Negative emotions emerged with participants using words like "weary", "anxious" and "scary", particularly "fear of serious consequences" when describing joint aspiration.

External factors included procedure-related factors like technical difficulty, and the type of joint to be aspirated. Consensus suggested that all joints except the knee should be left to the specialist. Context-related factors included time constraints. The group emphasised the importance of recurrent exposure and opportunity to practice aspirations. Availability of supervision influenced the decision to aspirate, particularly if by the rheumatologist.

Training in arthrocentesis appeared to be inconsistent. Positive comments included succinct dedicated training experiences by an expert using simulation, immediate feedback followed by practice. Negative comments emerged such as training was inconsistent and of poor timing, or trainees lacked the opportunity to subsequently practice. Participants then proposed methods of how to improve training in arthrocentesis.

Conclusions: The decision to aspirate is a complex interaction between internal and external factors combining knowledge, attitudes and emotions with circumstances and context. The participants emphasise training in knee aspirations, but not other joints due to lack of exposure. Immediate feedback during training in arthrocentesis is key. Inability to continue regularly practicing the procedure in real patients may be a barrier to retaining the skill. A review of training in joint aspiration may be required in order to improve uptake of this skill in practice.

Disclosure of Interest: None declared

DOI: 10.1136/annrheumdis-2017-eular.1250

\section{THU0596 RHEUMATOLOGY SPECIALTY TRAINING IN EUROPEAN UNION COUNTRIES}

N. Cikes ${ }^{1}$, J. Dudler ${ }^{2}$, F. Lioté ${ }^{3}$, D.E. Bax ${ }^{4}$, N.D.S. Bax ${ }^{4}$ on behalf of UEMS Rheumatology Section and Board Union Européenne des Médecins Spécialistes, Avenue de la Couronne 20, Bruxelles 1050. ${ }^{1}$ University of Zagreb School of Medicine, Zagreb, Croatia; ${ }^{2}$ Department of Rheumatology, HFR Fribourg Hôpital Cantonal, Fribourg, Switzerland; ${ }^{3}$ Rheumatology Department, Univ Paris Diderot, Inserm UMR 1132, Hospital Lariboisière, Paris, France: ${ }^{4}$ The Medical School, University of Sheffield, Beech Hill Road, Sheffield, United Kingdom

Background: The Union of European Medical Specialists (UEMS) seeks through its speciality Sections and Boards (S\&B) to enhance the training of its doctors and to encourage and support the movement of doctors between countries. The Rheumatology S\&B has delegates from all EU countries and has developed a document (European Training Requirements (ETR) - at uemsrheumatology.eu) that provides guidance about the rheumatology curriculum.

Objectives: To determine:

1. The extent of use of the Rheumatology ETR by EU countries

2. The extent of use of logbooks in recording the progress of a trainee

3. If training centres are accredited

4. If national assessment programmes exist for trainees

5. If a country has quality assurance and enhancement processes in rheumatology training

Methods: A questionnaire was sent to all S\&B members asking questions in relation to all of the objectives with one follow-up questionnaire to non-responders. Verification of responses as well as obtaining responses from continuing nonresponders occurred in December 2016.

Results: Nineteen countries responded. Most (18/19) have developed and implemented their own curriculum, often with the influence of the ETR, and also are using a logbook to record the progress of trainees. Training Centres are required to undergo accreditation in 15/19 countries. Another three countries are planning to introduce this. One country does not have an accreditation programme. After accreditation only 8 countries have quality assurance (QA) and enhancement (QE) programmes. In one of these countries the QA and QE processes are variable. Two other countries are either discussing or developing such processes. In 14 countries trainees are assessed to determine their suitability to become specialists. In one of these countries the approach is variable. Two other countries are planning to introduce assessments. Three countries do not assess their trainees.

Conclusions: Most EU countries have implemented their own, and varied, curricula for rheumatology training. All countries either use or are planning to use a portfolio, again variable in nature, to record trainees' progress. Thus, it appears that at present any pan-European standardised curriculum or logbook will be of limited utility.

Most countries require training centres to undergo accreditation. However, less than half of the countries have a continuation of quality assurance or quality enhancement processes after accreditation with some countries it seems having no plans to do so.

At present, a specialist in one European country is required by European law to be recognised as such in another. This study did not determine the nature of the assessments undertaken in different countries but this is not of current relevance within Europe as regards the possible movement of a doctor from one country to another for professional reasons.

Disclosure of Interest: None declared

DOI: 10.1136/annrheumdis-2017-eular.3314

\section{THU0597 FLIPPED LEARNING: CAN RHEUMATOLOGY LEAD THE SHIFT IN MEDICAL EDUCATION?}

Y. El Miedany ${ }^{1,1}$, M. El Gaafary ${ }^{2}$, N. El Arousi ${ }^{3}$, S.S. Youssef ${ }^{3} .{ }^{1}$ Rheumatology, Darent Valley Hospital, Dartford, United Kingdom; ${ }^{2}$ Community and Public health; ${ }^{3}$ Rheumatology and Rehabilitation, Ain Shams University, Cairo, Egypt

Background: Flipped Classroom is a model that is quickly gaining recognition as a novel teaching approach among health science. Flipped learning turns the usual teaching model on its head. The idea is that students learn new content outside the classroom (usually online) and then tackle assignments in lessons, giving tutors more time to help them with aspects they don't understand.

Objectives: 1. to implement a flipped classroom teaching for rheumatology topics for both under and postgraduate education. 2. to evaluate outcomes of teaching using a post-flipped classroom assessment and a student perceived effectiveness and satisfaction questionnaire.

Methods: Ten online videos on topics of how to take rheumatology history, individual joint examination, handling cases of monoarthritis and polyarthritis, and metabolic bone disease were made available for the students. 39 undergraduate 35 postgraduate trainees were included in this educational activity. The students were exposed to online lecture content prior to the class-time active learning session. The teaching session adopted an interactive learning environment and the course instructor served as a facilitator rather than a dominator for the instructional process, provided in-class applied learning opportunities and offered timely feedback/guidance to students. Evaluation of the teaching session was assessed using a scenario based learning and an evaluation check list. The students were asked to complete a questionnaire based on a 5-point Likert scale: 1 (strongly disagree) to 5 (strongly agree) to assess for their perceived effectiveness and satisfaction. The outcomes of the evaluation sheet and students questionnaire, were compared to 40 undergraduate and 34 postgraduate trainees who were taught in the last year on the same topics in a lecture-based model using the standard teaching protocols, followed by scenario based learning sessions, student evaluation and satisfaction survey.

Results: There was no significant difference regarding socio-demographics between the 2 students' groups included in this study. Outcomes of the flipped learning revealed that $94 \%$ of the students viewed the videos prior to the class session, and $96 \%$ attended the education sessions in comparison to $86 \%$ attendance in the traditional teaching group. Students reported an increase in knowledge, a positive learning experiences and perceptions of the flipped classroom model. Students' perceived effectiveness and satisfaction scores were significantly higher among the flipped learning in contrast to the traditional teaching comparative group (4.9 vs $4.3, p<0.05)$. Similarly, analysis of the students' assessment scores after the scenario based learning sessions was higher in the flipped learning group compared to the students taught by traditional methods $(p<0.01)$.

Conclusions: Implementation of the flipped learning for the rheumatology topics demonstrated a successful and promising platform for using technology to make better use of the students' time, and for increasing their satisfaction with the necessary didactic learning. Active learning increases student engagement and can lead to improved retention of knowledge.

Disclosure of Interest: None declared

DOI: 10.1136/annrheumdis-2017-eular.4501 